\title{
REFLEXÕES ACERCA DA FORMAÇÃO DOCENTE NOS CURSOS DE LICENCIATURA: POTENCIALIDADES DO ENTRELAÇAMENTO ENTRE PSICOLOGIA DA EDUCAÇÃO E PRÁTICA DE ENSINO
}

\author{
Rafael da Silva da CUNHA ${ }^{1}$ \\ Universidade Federal Rural do Semi-Árido (UFERSA) \\ rafael.dudu.r@gmail.com \\ Cynara Teixeira RIBEIRO ${ }^{2}$ \\ Universidade Federal do Rio Grande do Norte (UFRN) \\ cynara_ribeiro@yahoo.com.br \\ Alessandra Miranda Mendes SOARES ${ }^{3}$ \\ Universidade Federal Rural do Semi-Árido (UFERSA) \\ alessandrasoares@ufersa.edu.br
}

Resumo: $O$ presente trabalho visa analisar as contribuições das disciplinas Psicologia da Educação e Prática de Ensino nos cursos de formação docente, especialmente no âmbito da Licenciatura em Computação e Informática (LCI), como também apresentar uma experiência de entrelaçamento destas duas disciplinas, realizada a partir de um projeto de extensão. A escolha da LCI justifica-se pelo fato de ser recente no Brasil $e$ comprometer-se com a qualificação dos futuros professores para o uso das Tecnologias da Informação $e$ Comunicação (TICs) no processo educativo. A experiência consistiu na aproximação de licenciandos com a realidade de escolas circunvizinhas à Universidade, com foco nas percepções de como as TICs estão articuladas à prática pedagógica para a posterior elaboração de oficinas pertinentes às demandas institucionais. Através desta experiência vislumbramos práticas pedagógicas capazes de contribuir para o saber-fazer e o aprender a ensinar a partir da açãoreflexão-ação.

Palavras Chave: Formação Docente. Interdisciplinaridade. TICs.

\footnotetext{
${ }^{1}$ Estudante da Licenciatura em Computação e Informática da Universidade Federal Rural do Semi-Árido (UFERSA) e bolsista do Programa Institucional de Bolsas de Iniciação à Docência (PIBID/UFERSA).

${ }_{2}^{2}$ Professora do Centro de Educação da Universidade Federal do Rio Grande do Norte (UFRN) e Coordenadora de Gestão e Processos Educacionais do Programa Institucional de Bolsas de Iniciação à Docência (PIBID/UFRN). E-mail: cynara_ribeiro@yahoo.com.br

3 Professora da Universidade Federal Rural do Semi-Árido (UFERSA) e doutoranda do Programa de PósGraduação em Educação da Universidade Federal da Paraíba (UFPB). E-mail: alessandrasoares@ufersa.edu.br
} 
Abstract: The present work analyzes the contributions of disciplines Educational Psychology and Teaching Practice in teacher training courses, especially within the Degree in Computer and Informatics but also present a twining experience of these two disciplines, held from an extension project. The choice of the course is justified because it is recent in Brazil and commit to the training of future teachers for the use of Information and Communication Technologies (ICT) in the educational process. The experience was the approach of undergraduates with the reality surrounding schools to the University, focusing on perceptions of how ICTs are articulated to the pedagogical practice for the further development of relevant workshops to institutional demands. Through this experience we glimpse pedagogical practices that contribute to the know-how and learning to teach from the actionreflection-action.

Keywords: $\quad$ Teacher training. Interdisciplinarity. ICTs. 


\section{Introdução}

Pesquisas realizadas na última década apontam a permanência de problemas históricos no âmbito da formação de professores no Brasil, os quais dizem respeito tanto às legislações regulamentadoras quanto aos modelos e características dos cursos formadores (GATTI, 2010; SAVIANI, 2011; SHEIBE, 2010). No que tange aos cursos de formação inicial, as principais dificuldades são atribuídas à prevalência do modelo clássico de formação, o qual pauta-se em uma cisão entre formação disciplinar e formação para a docência, com a consequente fragmentação dos currículos e separação entre teorias e práticas (CANDAU; LELIS, 1999; GATTI, 2010; FRANCO, 2008; LELIS, 2001). Além disso, por ser calcado na lógica disciplinar, o modelo tradicional de formação induz os futuros professores a se afinarem mais com as demandas da área de conhecimento específica de seus cursos do que com as necessidades do campo educacional, não favorecendo, assim, o desenvolvimento de ações que enfatizem a produção do saber e do saber-fazer docente, o que implica em comprometer a relação teoria-prática proposta nos documentos legais e nas discussões sobre o tema (GATTI, 2010).

Nesta conjuntura, verifica-se uma pulverização da formação docente, a qual culmina em uma frágil preparação para a atuação no magistério, na medida em que o processo formativo é pouco integrado ao contexto concreto de atuação profissional (AZEVEDO ET AL, 2012; GATTI, 2010). Diante desta realidade, fica evidente a necessidade de mudanças nas concepções e práticas pedagógicas que orientam os cursos de formação inicial de professores, com destaque para as indicações de que a formação docente deve ser gerida a partir do seu campo de prática, o qual deve guiar os conhecimentos a serem aprendidos e o saber-fazer com situações advindas do cotidiano profissional, o que é avaliado como fundamental para uma formação qualificada (FRANCO, 2008; LELIS, 2001; CANDAU; LELIS, 1999; LIBÂNEO; PIMENTA, 1999).

Dessa maneira, torna-se crucial, nos cursos de formação inicial, a realização de projetos acadêmicos de caráter interdisciplinar, portadores de inovações significativas, calcadas em trocas de experiências, socialização de conhecimentos, articulações teóricopráticas e integração entre atividades de ensino, pesquisa e extensão (AZEVEDO ET AL, 
2012; CUNHA, 2004; ANDRÉ, 2011). É nesta perspectiva que se insere o presente estudo, o qual tendo como ponto de partida uma experiência desenvolvida em um curso de Licenciatura em Computação e Informática (LCI) objetiva analisar as contribuições das disciplinas Psicologia da Educação e Prática de Ensino nos cursos de formação docente, especialmente no âmbito da referida licenciatura, como também apresentar uma experiência de entrelaçamento destas duas disciplinas, realizada a partir de um projeto de extensão. Ademais, levando em consideração que tal experiência resultou da articulação entre os componentes curriculares de Psicologia da Educação e Prática de Ensino, considerados obrigatórios na matriz curricular e essenciais para a consecução das finalidades formativas dos cursos de licenciatura, discutir-se-á ainda os efeitos deste entrelaçamento para a compreensão concreta das relações entre teorias educacionais e práticas docentes, bem como entre os aspectos pedagógicos e tecnológicos necessários à promoção de uma incorporação de fato inovadora das Tecnologias da Informação e Comunicação (TICs) na educação, para o alcance das finalidades especificas propostas para cada curso de licenciatura.

\section{Desafios da formação docente nos cursos de licenciatura: a importância do diálogo teórico-prático interdisciplinar}

A formação docente é atualmente apontada como uma das dimensões mais importantes no tangente às possibilidades de melhoria da qualidade do ensino na Educação Básica (AZEVEDO ET AL, 2012; SEVERINO, 2004). Nesse sentido, são preocupantes os apontamentos acerca das lacunas encontradas ainda hoje nos cursos de formação inicial e continuada de professores (CUNHA, 2004; GATTI, 2010; FRANCO, 2008; SAVIANI, 2011). Dentre estas lacunas, destaca-se o papel atribuído e desempenhado pelas atividades práticas realizadas pelos professores ou futuros professores ao longo de sua formação, as quais podem revelar-se tanto como oportunidade para transformação da própria prática e dos sujeitos que dela participam quanto também como circunstância para a reprodução de um fazer mecânico, alienado e alienante (FRANCO, 2008).

Nos cursos de formação inicial, a dimensão prática da formação docente explicita-se na organização curricular principalmente através dos componentes voltados para a prática 
de ensino e para os estágios curriculares (CANDAU; LELIS, 1999; LELIS, 2001; LIBÂNEO; PIMENTA, 1999; MARANDINO, 2003). É nesse sentido que alguns documentos norteadores dos cursos de licenciaturas, partindo do pressuposto de que é a partir da dimensão prática que a formação inicial de professores vai se constituindo como lugar onde se aprende e se constroem os saberes da profissão, atribuem papel crucial aos componentes curriculares voltados à prática de ensino, preconizando sua interação com os saberes proporcionados por outros componentes de cunho teórico e teórico-prático existentes no currículo de cada curso (BRASIL, 2001, GATTI, 2010).

Porém, segundo as Diretrizes Curriculares Nacionais para a Formação de Professores para a Educação Básica, a dimensão prática da formação docente deve iniciar cedo e atravessar todo o currículo, propiciando ao futuro professor não apenas a elaboração de conhecimentos sobre o ensino e aprendizagem, mas também de conhecimentos nas e a partir das situações de ensino e aprendizagem (BRASIL, 2001). Para tanto, é necessário que a prática não se restrinja a componentes curriculares específicos, mas perpasse todo o processo formativo através de ações articuladoras que envolvam os eixos de pesquisa, ensino e extensão, mobilizando os múltiplos conhecimentos e saberes constituintes da formação docente, permitindo um diálogo interdisciplinar que fundamente o trabalho crítico-reflexivo sobre os confrontos que a prática suscita (ANDRÉ, 2011; AZEVEDO ET AL, 2012; FRANCO, 2008; PIMENTA; LIMA, 2004).

Nesse sentido, evidencia-se o papel fundamental da tríade ensino, pesquisa e extensão no processo de formação de professores, devido ao seu potencial para constituir-se como base para a produção de conhecimentos que sejam fonte de novos saberes (CUNHA, 2004). Além disso, levando em consideração a concepção segundo a qual um dos papeis dos professores na sociedade contemporânea é favorecer a emergência de novos saberes, bem como a transformação de realidades através de intervenções pautadas na reflexão teóricocrítica acerca dos conhecimentos produzidos ao longo do curso de formação (TARDIFF, 2002), as atividades de pesquisa e extensão, em sua articulação com o ensino, contribuem para uma maior compreensão da docência, tornando-se meios privilegiados para o 
aperfeiçoamento das práticas docentes e, consequentemente, para o aprimoramento dos processos de ensino-aprendizagem que ocorrem nos contextos educativos.

Assim, concebemos que a realização de projetos de ensino, pesquisa e extensão nos cursos de formação inicial de professores, ao ser capaz de promover uma articulação entre a dimensão prática do currículo, em especial dos componentes curriculares voltados à prática de ensino, e as disciplinas que constituem os fundamentos teóricos de tais cursos, como é o caso da Psicologia da Educação, favorecendo uma confrontação dos futuros professores com a sua realidade profissional, possibilita aos licenciandos uma atualização e ressignificação dos saberes adquiridos na formação inicial, convertendo-se, assim, em um suporte fundamental do processo de aprendizagem da profissão docente. Nesse sentido, através da realização de experiências que conjuguem os componentes curriculares voltados para a prática de ensino e os saberes constituídos a partir de outras disciplinas pertencentes aos currículos dos cursos de licenciatura, torna-se possível realizar o diálogo interdisciplinar e transformar a relação entre teoria e prática em uma práxis a partir da qual o futuro professor irá construir e elaborar seu fazer e seu saber-fazer pedagógico (CANDAU; LELIS, 1999; GATTI, 2010; FRANCO, 2008; LELIS, 2001).

Além disso, tais feitos possibilitarão ainda que os futuros professores ampliem sua consciência sobre o seu próprio fazer didático-pedagógico, o que, por sua vez, propiciará um avanço dos conhecimentos filosóficos, sociológicos, psicológicos e pedagógicos intrínsecos às próprias práticas docentes. Ou seja, a partir da proposição desta mudança no modelo de formação docente, objetiva-se que a prática docente experimentada pelos licenciandos alimente a teoria e subsidie outras práticas, em um movimento dialético constante e permanente que sustente o próprio processo de construção do conhecimento.

\section{Uma experiência a partir da imersão na realidade escolar: percebendo a confluência entre os saberes}

Com vistas a promover uma experiência interdisciplinar, capaz de integrar os conteúdos aprendidos nos componentes curriculares de Psicologia da Educação e Prática de Ensino de um curso de Licenciatura em Computação e Informática, foi elaborada, pelas 
docentes responsáveis pelas referidas disciplinas, uma proposta de atividade a ser realizada em escolas de educação básica da região do semiárido potiguar. Tal proposta consistia em levar os licenciandos que cursavam tais componentes a desenvolverem uma pesquisa de campo que envolvia: a elaboração de um diagnóstico escolar, a observação de aulas ministradas por alguns professores e a realização de entrevistas com estes, gestores e estudantes das escolas, a fim de compreender como as tecnologias estavam articuladas às práticas pedagógicas das instituições de ensino investigadas, buscando ainda averiguar as concepções e os fundamentos teórico-práticos que as embasam a partir das abordagens existentes na psicologia da educação e na prática de ensino em computação.

Assim, a premissa que orientou a realização desta experiência foi a de que conhecer, refletir e analisar as práticas pedagógicas desenvolvidas nas escolas de educação básica contribui de forma significativa para uma boa formação do profissional docente. Isso porque, conforme apontado anteriormente, os estudos acerca da prática conduzem inequivocamente a uma reelaboração da mesma, advindo daí a possibilidade de avanços tanto acerca das teorias como da práxis educativa.

\section{Método}

A experiência ora relatada foi realizada por um grupo de estudantes do segundo período do curso de Licenciatura em Computação e Informática, consistindo em uma atividade curricular pensada para integrar as duas disciplinas. Através de sua realização, foi possível conhecer as realidades educacionais de cinco escolas públicas situadas em municípios circunvizinhos ao da Universidade, bem como algumas ações docentes de 16 professores dessas instituições, incluindo os diferentes materiais e métodos utilizados, os modos particulares de relacionamento entre professores, estudantes e equipe escolar, bem como a estrutura física e educacional, para, a partir daí, refletir sobre as possibilidades e potencialidades do entrelaçamento entre teorias educacionais e práticas pedagógicas tanto no âmbito da formação de professores quanto no que tange às ações docentes com o uso das TICs no cotidiano escolar. 
A pesquisa realizada nas escolas teve um enfoque qualitativo, por considerar a importância de uma compreensão detalhada dos significados e características situacionais apresentadas. Para tanto, foram utilizados os seguintes instrumentos: observação, entrevista e questionários. Os resultados obtidos serão discutidos à luz das reflexões acerca dos desafios para a formação docente, esboçadas nos itens anteriores.

\section{Resultados}

De modo geral, observou-se que a organização dos espaços escolares e as práticas pedagógicas existentes nas instituições de ensino pesquisadas fundamentam-se nos princípios da pedagogia tradicional, na qual as relações entre professores e estudantes são geralmente concebidas de forma hierarquizada, na medida em que aqueles se veem como detentores do saber, delegando aos últimos a posição de quem ainda não sabem e, portanto, deverão aprender através da memorização e reprodução dos conhecimentos academicamente instituídos. Nessa perspectiva, estes são encarados como meros ouvintes e a aprendizagem tende a ocorrer de forma mecânica, sem favorecer a construção coletiva e criativa de novos saberes.

Já nas entrevistas realizadas com os professores, constatou-se que, em sua maioria, eles não fazem uma autorreflexão acerca de sua própria atuação, não percebendo, portanto, os momentos em que são reprodutores do modelo calcado na educação tradicional. Para exemplificar esta situação, é possível citar um dos professores observados que começou uma de suas aulas dizendo: "abram os cadernos na última atividade sugerida como tarefa para casa, que eu irei chamá-los um a um na ordem da folha de chamada para verificar se vocês responderam as questões"; mas, ao ser interrogado acerca do método de ensino que utiliza, respondeu que "passou-se o tempo em que o professor é aquele que só deposita a mensagem, o dono do saber, [...], antes era só assim, o professor dizia, acabou, o aluno não questionava, era o aluno passivo, já hoje existe uma relação muito forte com aluno e professor, nessa ponte 
de ensino e aprendizagem", demonstrando, acerca deste ponto, incoerência entre seu discurso e seu agir.

De fato, para Freire (1985), a forma imperativa de transmissão dos conhecimentos, característica do modelo tradicional, apenas reforça a dominação cultural e política, impedindo a conscientização dos seres humanos e sua formação como cidadãos. Nesse sentido, a perspectiva freireana aponta que:

[...] ensinar não é transferir conhecimento, mas criar as possibilidades para a sua própria produção ou a sua construção. Quando entro em uma sala de aula devo estar sendo um ser aberto a indagações, à curiosidade, às perguntas dos alunos, as suas inibições, um ser crítico e inquiridor, inquieto em face da tarefa que tenho - a ele ensinar e não a de transferir conhecimento (FREIRE, 1996, p. 47).

É importante salientar que esta concepção de ensino reflete-se no modo como cada professor realiza suas ações, a começar pelo seu planejamento, pois, na perspectiva de uma pedagogia progressista, sabemos que este precisa ser flexível, já que há uma diversidade de fatores que podem fazer com que o profissional precise fazer modificações, reformulando, na prática, o que planejou aprioristicamente. Isso significa que os planos de aula não podem converter-se em "camisas de forças", mas, pelo contrário, precisam levar em consideração que o ritmo, a sequência, o ponto de partida e de chegada de cada aula variam de acordo com os conhecimentos prévios e as realidades socioeducacionais dos estudantes.

Um dos professores observados demonstrou tal flexibilidade quando, ao começar a ministrar o conteúdo proposto, pediu que cada estudante expressasse o que já conhecia sobre o referido assunto, levando em consideração tais conhecimentos prévios ao longo da condução da aula. Esta postura de respeitar o conhecimento prévio dos educandos é defendida por diversas teorias educacionais, que afirmam que a aprendizagem é um processo de construção que nunca começa do zero, nem mesmo nos momentos iniciais da escolaridade, já que os aprendizes sempre trazem consigo conhecimentos adquiridos através de experiências com suas famílias ou outras instituições sociais por quais tenham passado. Assim, concebe-se que o aprender é um processo que envolve diversas etapas, nas quais as ideias dos estudantes vão sendo gradativamente ampliadas, reformuladas ou reorganizadas, 
em um movimento simultaneamente ascendente e descendente, no qual os conhecimentos prévios servem de base para a construção de conceitos científicos e estes, por sua vez, se materializam a partir e nos conhecimentos do dia a dia (VYGOTSKY, 2007).

Ainda no que diz respeito às práticas pedagógicas e estratégias didáticas utilizadas pelos professores das escolas investigadas, foi possível constatar a utilização de uma diversidade de metodologias, que vão desde as aulas expositivas tradicionais, com utilização do quadro-negro e livros didáticos, até atividades em que os estudantes são convidados a desempenhar a função de professores, explicando conceitos ou formas de resolução das questões para os próprios colegas - momento em que é possível perceber os estudantes como sujeitos ativos da aprendizagem, tal como preconizado pelas teorias pedagógicas modernas.

Outra estratégia destacada pelos professores da educação básica que participaram da experiência ora relatada diz respeito à relação professor-aluno, pois muitos dos docentes observados e entrevistados demonstraram preocupação em manter uma postura profissional adequada, que possa auxiliar no desenvolvimento dos educandos, que não seja rígida nem autoritária, mas, pelo contrário, baseada no respeito mútuo e na parceria, a fim de possibilitar uma melhor aprendizagem. Nessa perspectiva, os professores assumem como dever motivar, desafiar e instigar os estudantes, favorecendo o diálogo, a troca de ideias e, consequentemente, o desenvolvimento de todos os envolvidos no processo de ensinoaprendizagem.

Além disso, um dos professores entrevistados destacou a contextualização do conteúdo como estratégia didático-pedagógica privilegiada para a facilitação da aprendizagem. Segundo ele, "se eu ensinei agora uma questão e o aluno não entendeu, eu tenho que ter outra forma de ensinar aquela mesma questão: amenizar a linguagem, contextualizá-la no dia-a-dia daquele aluno, pois, abordar o dia-a-dia dele é um jeito de motivá-lo a prestar atenção, a entender”. De fato, não apenas a contextualização do conteúdo ensinado a partir da realidade de vida do educando facilita a assimilação dos conhecimentos como também a utilização de materiais que são familiares aos estudantes atendem a este fim, como é o caso de recursos e ferramentas tecnológicas que muitos utilizam tanto em casa como em lan houses, com amigos etc., para a realização de atividades diversas. 
Especificamente no tocante aos recursos tecnológicos utilizados nas escolas visitadas, constatou-se que alguns professores afirmam lançar mão de ferramentas midiáticas, tais como datashow, vídeos, softwares educativos etc. Importante ressaltar que estes recursos podem constituir-se tanto como instrumentos culturais quanto simbólicos, na medida em que potencialmente funcionam como mediadores entre os aprendizes e os conhecimentos formalmente instituídos. Porém, discussões atuais apontam que, para um uso pedagogicamente significativo das TICs na educação, é necessário pensar como as tecnologias podem ser usadas de forma a não constituírem-se apenas como instrumentos os quais os seres humanos usam para agir fisicamente sobre o seu meio, mas também enquanto capazes de intervir na atividade mental e nos processos cognitivos envolvidos na aprendizagem escolar, desempenhando, assim, uma função simultaneamente cultural e simbólica, de forma semelhante às várias formas de linguagem (FREITAS, 2008).

Nesse sentido, pode-se afirmar que as TICs "abrem novas possibilidades de aprendizagem por permitirem o acesso a uma infinidade de informações, pelas formas de pensamento que são por elas potencializadas, pelas interações possibilitadas e pela interatividade que proporcionam" (FREITAS, 2008, p. 12), tornando-se, assim, um dos principais recursos de mediação pedagógica a serem utilizados pelos professores. No entanto, a integração pedagogicamente eficaz destas ferramentas tecnológicas em sala de aula constitui-se como um desafio para os profissionais docentes, os quais, em sua maioria, não recebem, em sua formação inicial, uma capacitação adequada e, em função disso, acabam não utilizando ou utilizando erroneamente tais instrumentos em sua prática pedagógica.

De acordo com Masetto (2000), a utilização de computadores e da internet no processo de ensino-aprendizagem requer não apenas a substituição do quadro-negro e do giz por novas tecnologias informatizadas, mas sua utilização enquanto instrumentos capazes de atuar no desenvolvimento intelectual de estudantes, professores e demais atores do cenário escolar. Em perspectiva semelhante, Freitas (2008) afirma que as TICs são instrumentos de linguagem, pois seu funcionamento depende de símbolos, o que as permite desempenhar as três ordens de mediação necessárias à construção do conhecimento: a mediação material, na medida em que são ferramentas materializadas; a mediação semiótica, através da linguagem; 
e a mediação com os outros, haja vista que possibilitam a interação com diversos interlocutores. Isso significa que a informática na educação inaugura, potencialmente, maneiras inéditas de procurar informações, acessá-las, representá-las, processá-las, comunicá-las e compartilhá-las, constituindo, portanto, um novo sistema simbólico que pode ser usado por estudantes e professores para planejar, regular e orientar as atividades próprias e alheias.

Porém, a despeito dos possíveis avanços propiciados pelas TICs na educação, algumas escolas e professores apresentam dificuldades para incorporá-las no dia a dia das salas de aula. É o caso de um dos professores observados, que afirmou ainda não usar as tecnologias como recurso pedagógico em suas aulas devido aos problemas enfrentados no que diz respeito à disponibilidade de tais ferramentas. Segundo ele, apesar de a escola dispor de um laboratório de informática, com aproximadamente quinze computadores, além de softwares e jogos educativos, há uma limitação referente à quantidade de máquinas, já que, para ele, deixar muitos estudantes em uma mesma máquina interfere negativamente nos resultados da aprendizagem.

A partir dos referenciais pedagógicos modernos, percebemos que este argumento pauta-se em uma concepção de aprendizagem como um processo de cunho exclusivamente individual, ignorando, portanto, as potencialidades envolvidas no trabalho em grupos e, consequentemente, a noção de aprendizagem colaborativa. Vale ressaltar que este é, de fato, um dos grandes desafios no que tange ao uso das tecnologias no contexto educacional, haja vista pesquisas revelarem ser mais comum a utilização das TICs nas escolas com o objetivo de aumentar e melhorar o acesso às informações do que os usos relacionados à exploração, colaboração e criação coletiva de conhecimento. Tal fato é consonante com o predomínio uma visão transmissiva de ensino e aprendizagem, de modo que, nessa perspectiva, as TICs, quando utilizadas, o são com a finalidade de reforçar as estratégias docentes de apresentação e transmissão de conteúdos (COLL; MAURI; ONRUBIA, 2010).

Também costuma ser frequente que os professores, apesar de não fazerem uso de recursos tecnológicos em sala de aula, estimulem os estudantes a fazerem pesquisas na internet para a realização de tarefas escolares. Este tipo de incentivo foi observado em 
algumas escolas investigadas. Porém, na visão da maioria dos estudantes, é muito mais proveitoso quando esta ferramenta é integrada ao contexto da aula, como nos casos em que os professores desenvolvem suas atividades no laboratório de informática, pois, segundo um dos estudantes entrevistados, "o que às vezes não se encontra em sala de aula, se encontra na internet; as dúvidas que surgem são facilmente tiradas com o auxilio dessa ferramenta, e isto facilita a aprendizagem". Desse modo, foi possível constatar que, na perspectiva dos aprendizes, as ferramentas tecnológicas, tais como o computador e a internet, ocupam papel de destaque, sendo reconhecidas como indispensáveis para o alcance de melhores resultados na educação, na medida em que podem tornar as aulas mais interessantes e produtivas.

Assim, a partir da realização desta experiência, foi possível constatar que, apesar de a incorporação da informática na educação não ser uma tarefa fácil para o profissional docente, esta pode ser realmente produtiva e inovadora, tanto do ponto de vista dos estudantes, como de professores e gestores. Isso porque, por intermédio dos bancos de dados em linha, da rede mundial de computadores, de conferências eletrônicas desterritorializadas, entre outros meios, informações atualizadas tornam-se diretamente acessíveis e comunicáveis (LÉVY, 1999). Nesse contexto, a função do docente deixa de ser a de transmissor de informações, a qual é executada com maior eficácia por aqueles meios, e passa a ser a de incentivar o pensar, através do acompanhamento e gerenciamento dos aprendizados, incitando o intercâmbio dos saberes e a mediação simbólica entre estudantes, professores e conteúdos.

Porém, para que essa utilização eficaz e pedagogicamente significativa das tecnologias seja possível, é necessário que os professores tomem como ponto de partida a análise de suas próprias práticas, confrontando-as com os diversos referenciais educacionais disponibilizados pelo conjunto de saberes os quais compõem a formação docente. É nesse sentido que os cursos de formação inicial de professores têm a função de proporcionar aos licenciandos um conhecimento da práxis educativa capaz de instrumentalizar uma postura de valorização e atualização permanente em função das mudanças que se produzem, fazendoos criadores de estratégias e métodos de intervenção, cooperação, análise e reflexão transformadores da prática educativa. 


\section{Considerações Finais}

As dificuldades e limitações, historicamente existentes nos cursos de formação de professores, são bastante conhecidas e envolvem principalmente a cisão entre teoria e prática, a fragmentação dos saberes em componentes curriculares específicos e pedagógicos em cada curso, e a desarticulação entre os conhecimentos científicos e a realidade socioeducacional. Tais empecilhos estão intrinsecamente relacionados ao modelo tradicional de formação de professores, o qual precisa ser superado para possibilitar práticas pedagógicas socialmente mais relevantes.

No entanto, reconhece-se que a real superação desse modelo tradicional de formação exige a realização de ações concretas associadas a um posicionamento teórico-metodológico aberto a críticas e atualizações. Isso aponta para a necessidade de embasar as ações pedagógicas a serem desenvolvidas nos cursos de licenciatura e de repensar o próprio currículo dos mesmos a partir de experiências concretas, superando reducionismos quanto às simples mudanças nas cargas horárias das atividades curriculares e de meros ajustes do currículo às demandas do mercado. Dessa maneira, torna-se necessário superar a formação baseada na memorização e na aplicação acrítica de saberes descontextualizados e subsidiar a reflexão e a problematização contínuas, por parte dos licenciandos, para que estes possam se apropriar do conhecimento didático-pedagógico e desenvolver as competências imprescindíveis para a atuação docente.

Assim, experiências de caráter teórico-prático e interdisciplinar têm muito a agregar aos cursos de formação de professores, na medida em que possibilitam a inserção dos licenciandos no cotidiano das escolas e favorecem a troca de saberes entre os professores da educação básica, os professores da Universidade e os acadêmicos, estimulando, assim, uma postura comprometida com a práxis. Dessa forma, o aprender a ensinar a partir da açãoreflexão-ação, na qual há uma indissociabilidade entre teoria e prática, visa possibilitar aos licenciados as condições éticas, técnicas e pedagógicas necessárias à qualificação do trabalho docente. 


\section{Referências}

ANDRÉ, Marli. A formação dos professores nas pesquisas do anos 90. In: MACIEL, Lizete; SHIGUNOV NETO, Alexandre (Orgs.). Formação de professores no Brasil - passado, presente e futuro. $2^{\mathrm{a}}$ ed. São Paulo: Cortez, 2011. p. 77-96.

AZEVEDO, Rosa Oliveira; GHEDIN, Evandro; SILVA-FORSBERG, Maria Clara; GONZAGA, Amarildo Menezes. Formação inicial de professores da educação básica no Brasil: trajetórias e perspectivas. Revista Diálogo Educacional, Curitiba, v. 12, n. 37, p. 997 1026, set./dez. 2012.

BRASIL. Plano Nacional de Educação - Lei 10.172. Ministério da Educação: Brasília-DF, 2001.

CANDAU, Vera; LELIS, Isabel Alice. A relação teoria-prática na formação do educador. In: CANDAU, Vera (Org.). Rumo a uma nova didática. 10ª ed. Petrópolis: Vozes, 1999. p. 5672 .

COLL, César; MAURI; Teresa; ONRUBIA, Javier. A incorporação das tecnologias da informação e da comunicação na educação: das práticas pedagógicas às práticas de uso. In: COLL, César; MONEREO, Carles (Orgs.). Psicologia da educação virtual: aprender e ensinar com as tecnologias da informação e da comunicação. Porto Alegre: Artmed, 2010. p. 66-93.

CUNHA, Maria Isabel. Diferentes olhares sobre as práticas pedagógicas no Ensino Superior: docência e formação. Revista de Educação, Porto Alegre, v. 3, n. 54, p. 525-536, set. 2004.

FRANCO, Maria Amélia. Entre a lógica da formação e a lógica das práticas: mediação dos saberes pedagógicos. Educação e Pesquisa, São Paulo, v. 34, n. 1, jan./abr. 2008. p. 109-126.

FREIRE, Paulo. Pedagogia do Oprimido. 9a ed. Rio de Janeiro: Paz e Terra, 1985.

Pedagogia da autonomia: saberes necessários à prática educativa. $15^{\mathrm{a}}$ ed. São Paulo: Paz e Terra, 1996.

FREITAS, Maria Teresa de Assunção. Uma reflexão a partir da abordagem psicológica histórico-cultural. Anais eletrônicos do $2^{\circ}$ Simpósio Hipertexto e Tecnologias na Educação. Universidade Federal de Pernambuco, 2008. 
GATTI, Bernadete. Formação de professores no Brasil: características e problemas. Educação \& Sociedade, Campinas, v. 31, n. 113, p. 1355-1379, out./dez. 2010.

LELIS, Isabel Alice. Do ensino de conteúdos aos saberes do professor : mudança de idioma pedagógico? Educação \& Sociedade, Campinas, v. 22, n. 74, p. 43-58, abr. 2001.

LÉVY, Pierre. Cibercultura. São Paulo: Editora 34, 1999.

LIBÂNEO, José Carlos; PIMENTA, Selma Garrido. Formação de profissionais da educação: visão crítica e perspectiva de mudança. Educação \& Sociedade, Campinas, v. 20, n. 68, p. 239-277, dez. 1999.

MARANDINO, Martha. A prática de ensino nas licenciaturas e a pesquisa em ensino de ciências: questões atuais. Cadernos Brasileiros de Ensino de Física, v. 20, n. 2, p. 168-193, ago. 2003.

MASETTO, Marcos Tarcísio. Mediação pedagógica e o uso da tecnologia. In: MORAN, José Manuel; MASSETO, Marcos Tarcísio; BEHRENS, Marilda Aparecida. Novas tecnologias e mediação pedagógica. Campinas: Papirus, 2000. p. 133-173.

PIMENTA, Selma Garrido; LIMA, Maria Socorro Lucena. Estágio e Docência. $1^{\mathrm{a}}$ ed. São Paulo: Cortez, 2004.

SAVIANI, Dermeval. Formação de professores no Brasil: dilemas e perspectivas. Poíesis Pedagógica, Goiânia, v. 9, n. 1, jan./jun. 2011. p. 7-19.

SEVERINO, Antonio Joaquim. A produção do conhecimento na Universidade: ensino, pesquisa e extensão. Educação \& Linguagem, v. 7, 2004. p. 9-14.

SHEIBE, Leda. Valorização e formação de professores para a educação básica: questões desafiadoras para um novo plano nacional da educação. Educação \& Sociedade, Campinas, v. 31, n. 112, jul./set. 2010. p. 981-1000.

TARDIFF, Maurice. Saberes docentes e formação profissional. Petrópolis: Vozes, 2002.

VYGOTSKY, Lev Semenovich. A formação social da mente. São Paulo: Martins Fontes, 2007. 